\title{
DESIGNING, IMPLEMENTATION, EVOLUTION AND EXECUTION OF AN INTELLIGENT MANUFACTURING SYSTEM
}

\author{
Pawan Sharma ${ }^{1}$, Dr. Manish Bhargava ${ }^{2}$ \\ Department of Mechanical Engineering \\ Maharishi Arvind Institute of Engineering and Technology \\ Sector-7, Madhyam Marg, Mansarovar, Jaipur, Rajasthan, India-302020
}

\begin{abstract}
This paper shows a framework of the different techniques for the design of the planning and governing components, implementation, Evolution and execution of an intelligent manufacturing system. Architecture of a modern manufacturing industry is presented, which makes possible to create specific manufactrons system for the specific tasks, depending on the self-operated analysis of its essential characteristics. The manufactronic industry concept helps in the integration of intelligence and to increase flexibility at the maximum level of the manufacturing system as well as at the minimum level of the particular machine. This concept is implemented \& demonstrated in the automobile and aeronautical industries, but can be simply applied to nearly all manufacturing industries. Implementation of manufactronic techniques in the industries helps to forecast and to fulfill the rapidly varying customer requirements, to produce high quality products in sufficient quantities with reduction in costs. The Modern Intelligence Technologies are also presented in this paper.
\end{abstract}

\section{KEYWORDS}

Design, Execution, Evolution, Implementation, Intelligent Manufacturing System (IMS) and Production Unit.

\section{INTRODUCTION}

In the global environment of complex industrial manufacturing and in the era of higher efficiency, larger flexibility, better product quality and reduced cost, the manufacturing system changes a lot. Since the early 50s when classical manufacturing control was applied, engineers have invented various procedures which analyze or design manufacturing systems. The purpose of implementation of intelligent manufacturing system meets the challenge to satisfying rapidly varying customer requirements at the most efficient level for lowest possible cost same as any normal manufacturing system.

Not only the involvement of computers in manufacturing system makes it the intelligent manufacturing system, the decision making ability of manufacturing systems like a human being makes it "Intelligent". In meticulous information base systems have subject the manufacturing landscape of late 1990's CIM was all rage in 1980s, FMS in 1970s. Innovative data based manufacturing technology plays an significant role in future human growth. We can see and get the effect of knowledge based system on manufacturers. Any association must make full lead of the knowledge at its disposal. This goal transforms into the effective use of knowledge from design to invention and maintenance. To this end, the information captured in disparate modules

DOI : 10.14810/ijmech.2014.3314 
in the association must be enlightened and directed synergistically to support integrated systems for manufacturing and fabrication. There is a lack of wakefulness of tools and techniques to be used among manufacturers. Industries frequently use existing tools rather than looking up benefits of intelligent manufacturing systems due to lack of consciousness of tools and techniques to be used. Intelligent system vendors assist to improve situation by their modules to fit defined necessities for successful industrialized practice [6].

\section{The Concept OF an InTElligent MANufaCturing System}

A process of producing a product with the help of material, men as labor, power as energy, and equipment, known as manufacturing. The products produced by the manufacturing always have better value than the total sum of material used in. This can be easily understood by a given system in figure 1. Here the contribution of product produced involves labor, material, energy and capital. The assets parameter is used to provide the equipment and amenities necessary to brought together the material, labor, and energy. Output involves product along with residual and fragment. The residual \& fragment are some unwanted output, which should not be erratic. The construction of automobiles, airplanes, refrigerators and electronics would be acknowledged as manufacturing [2].

Before look into manufacturing systems and application issues, it is essential to have an overview of the operation of manufacturing functions. What are the objectives of manufacturing? In a wide sense they are:

- Production,

- Productivity,

- Quality.

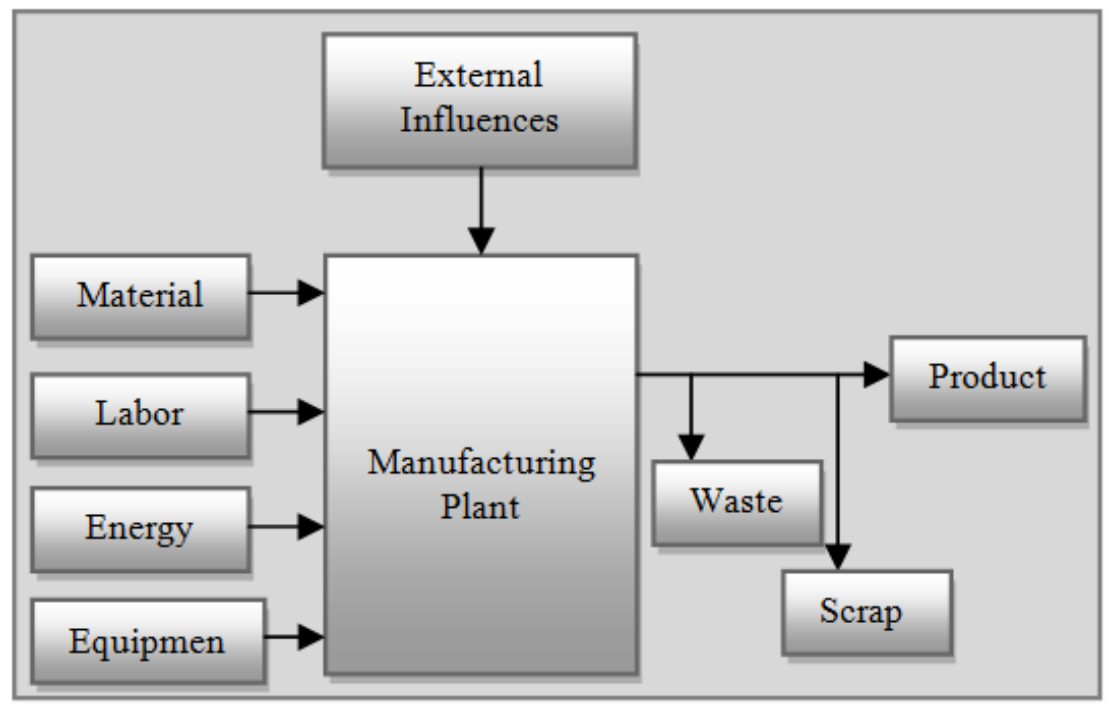

Fig. 1: Manufacturing System

From the important aspect of manufacturing Cost \& quality, manufacturing systems must fulfill a number of fundamental requirements:

- Full integration of incorporated software and classical hardware systems within an enterprise, 
- Open system design to accommodate new subsystems (software or hardware) or separate existing subsystems,

- Efficient and effective communication medium and cooperation among departments within an enterprise and among enterprises,

- Personification of human factors into manufacturing systems,

- Quick response to rapidly changing orders and sudden disturbances from both internal and external manufacturing environments,

- At the system \& subsystem both levels full tolerance, as to easy detection and recovering from system failures and minimize their impacts on the workflow environment [4].

\section{Components of An InTElligent ManufaCturing System}

The manufacturing process can be decomposed into several components. Rao et al. (1993) decomposed the intelligent manufacturing systems into the following components:

- Intelligent Design,

- Intelligent Operation,

- Intelligent Control,

- Intelligent Planning and,

- Intelligent Maintenance [3].

We modify this decomposition slightly to reflect the current trends on intelligent manufacturing systems into the following components:

- Intelligent Maintenance \& Diagnosis,

- Intelligent Process Planning,

- Intelligent Quality Management,

- Intelligent Scheduling,

- Intelligent Control,

- Intelligent Design.

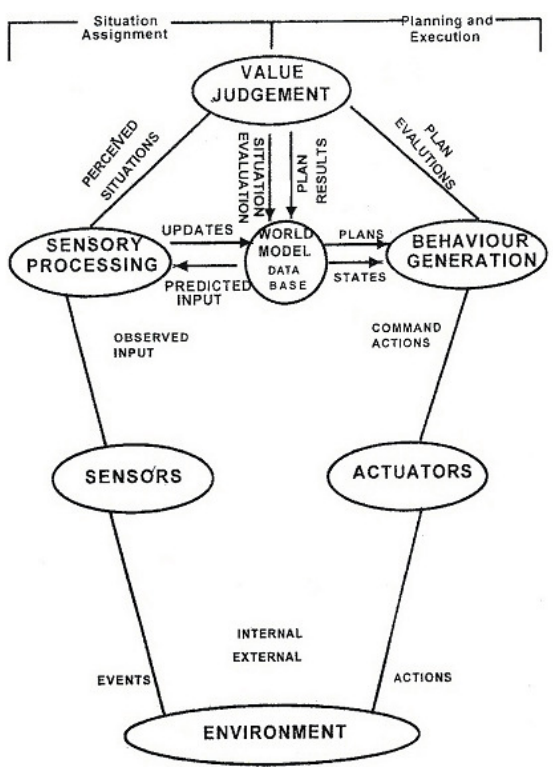

Fig. 2: Building Block of an Intelligent System 


\section{INTELligent MANUfacturing SySTEMs DeSign}

The Design approach shows, an Intelligent Manufacturing System is a self operated system, which is able to self regulate and self control the manufacturing system within the specified design conditions. The Intelligent Manufacturing System design uses the basic rules and regulations of the object in which modeling of information and sequence is concurrent.

The design of an object is based on single conceptual theory. The working assumptions of design and implementation made on the basis of Computer Integrated Manufacturing Open Systems Architecture (CIMOSA). CIMOSA introduced with a new integrated modeling methodology for the enterprises based on its processes. CIMOSA architecture theory defined the enterprise as a set of domains made of organizational processes realizing the basic aims of the enterprise activity [1].

In this approach the assumption is, the domain may be defined for several parts of the enterprise activity, implementing several manufacturing functions, while the processes of enterprise organizations are linked to market environment.

On the basis of problem analysis conducted and the presented methods taking into account, the following are the basic rules for designing the Intelligent Manufacturing System:

1. Intelligent System of Manufacturing should be formed as open modular structure design system that would allow for their development, thus the possibilities range will get extend in design and function processing.

2. The designed Intelligent System of Manufacturing should be created into flexible system and competent of learning from experience.

3. An Intelligent Manufacturing System of distributed pattern should be developed to be equipped with possible ways of parallel information processing in order to raise its efficiency in gathering and conveying a huge amount of information. It is necessary to utilize the current information technologies with local and global network of computers.

4. Extensive application of multimedia technology, computer graphics (CG) and hypertext in the presentation of information [3].

\section{IMPLEMENTATION OF AN INTELLIGENT MANUFACTURING SYSTEM}

The implementation of Expert System approaches with this concept of intelligence addition. The Current development in feature based solid modeling techniques for design illustration and its applications have exposed a potential to deputy Expert Systems for some decisions presently operated by designers knowledge of design policy and practices [1].

Intelligent System of Manufacturing can be achieved in these three basic ways:

1. By using of monitoring and controlling manufacturing conditions, existing manufacturing process become intelligent.

2. By adding the sensors to control and monitor the state of processed product, existing processes become intelligent.

3. By using the New Processes of intelligent designing, the desired quality of parts can be achieved.

The Intelligent Manufacturing System (IMS),

- Uses the technologies which are fully automated, can minimize the use of human Brain,

- Self-operated processes with automatic feedback mechanism, 
- Automatic Monitoring and control of the manufacturing Processes,

- Self-Monitoring and controlling of the state of processed product.

The Steps for the implementation in an intelligent Manufacturing system are as follows:

1. Select an already available software that will first enhance an expert system and then combine with task solution software,

2. Collect trade values, heuristic policy, precedent experiences and suggestion from books, experts and standard codes,

3. Categorize a whole set of rules leading this task, and illustrate them in a proper way suitable to a list processing software,

4. Create a list of features and attributes of other part, called for in the rule set,

5. Create significant data by extracting the features and other essential attributes of the part from the model information of an object,

6. Categorize the rules leading this task into a information base,

7. Implement an inference system as a analysis mechanism to come across the solution on the information base and the peripheral data,

8. Integrate the results into the model and its illustration to get an absolute solution.

\section{Evolution OF MANUfaCturing SySTEMS}

\subsection{Cost - Based Manufacturing}

- After World War II - Economic prosperity in USA created a tremendous demand for manufactured products.

- Selling price - Primary Source of competition between manufactures.

- Reducing manufacturing costs - mandatory to generate higher profits.

- Cost reduction - led to a great deal of standardization and automation.

- Consumers benefited - from the availability of - previously unheard - of quantities of low cost products.

- However huge demand for products to a "seller market".

- Industries benefited - any reduction in cost or increase in production translated into higher profits.

- Industries ignore consumer needs - $\quad$ Product quality.

- Effects only on cost reduction - $\quad$ Not on the development of new products Improvement of current products

\subsection{Quality Based manufacturing}

- In 1970's - market for manufactured goods - becomes global.

- American manufacturing companies found themselves with competition with Japan elsewhere.

- Variety of products available.

- Consumers had a choice on variety of foreign and domestic products.

- This shifts in market condition.

- Pressure on manufacturers.

- In addition to cost reduction and product quality - to compete in the market.

- Every manufacturing industry instituted some kind of quality program -

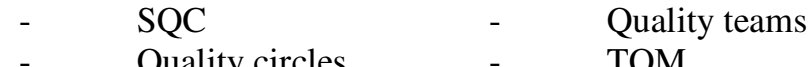

Quality circles $\quad-\quad$ TQM

- Level of quality available in the market place increased dramatically. 


\subsection{Time Based Manufacturing}

- By 1990’s - Many manufacturing companies capable of providing,

$$
\text { - High quality and low cost, }
$$

- $\quad$ Products to global market.

- Consumers had options

- Many companies had one thing in common - Responsiveness

- $\quad$ Responded quickly to customer needs and desires,

- $\quad$ Responded quickly to shifting demand by quickly adjusting production,

- $\quad$ Responded quickly to problems and changing conditions in their factories.

- A new kind of pressure - Time Pressure

- Consumers - not satisfied with products of

- Low cost,

- High quality.

- They wanted to have the products delivered with same speed as standard products

- They demanded diversity in products lines - Pushed quantity to low.

- Companies had to offer any diversified products.

\subsection{Newer Concept Emerged}

- AGILE MANUFACTURING

- BPR

- FMS

Many more concepts are evolving

Still low cost,

High quantity,

Responsiveness,

Keep the company in the market.

\subsection{Information - Based Manufacturing}

We are now in information age

- Information important than physical goods

- Knowledge is power

- Companies with most information - Most powerful

- Now pressure - Pressure of Information

- Customer wants - Information about products

- $\quad$ Date of manufacturing

- $\quad$ Options included

- Operating instructions

- $\quad$ Source of replacement parts

- Simple printed owner's manual - No longer be adequate.

- Must be replaced by

- Sophisticated Multimedia information package.

- Customer will demand -

- Videotapes - to install / operate product

- Interactive CD - ROMs for training

- E-mail / Fax access to get product information

- Internet web pages with

- Latest product information 
- Information on recalls

- Information on compatibility issues

- Information on product changes

- and so on...

\subsection{Virtual Manufacturing}

Used today to describe manufacturing systems that are actually combinations of systems owned \& operated by served companies.

Various participating companies may represent -

- Engineers and Designers

- Raw material suppliers

- Manufacturers of various parts

- Assemblers

- Packages

- Financial and accounting people

- VMS - will be created to produce a product or products and then be modified or destroyed.

- Participated in VMS - geographically widely distributed.

- May represent a variety of traditional industries.

- Information links will be exchanged rapidly, and so that the manufacturing process can be coordinated.

- Current systems are integrated manufacturing systems with little amount of flexibility.

- If the systems are intelligence, flexibility level will be increased.

\section{EXECUTION OF AN INTELligent MANUFACTURING SySTEM}

The initial edge in the execution of the processes to produce a part is that the raw materials and tooling are brought together with production equipment's such as Numerical Control Machines. This initial step also includes the finishing of the parts, checking and testing and safe the parts in storage until required.

The next step in the execution of processes includes parts and tooling together along with other manufacturing processes such as robots for assembles the products. Also finishing, inspecting, testing, and storing may be essential [7].

Execution of Manufacturing System controls the production operations that enable the realization of management plans and provides feedback from the plant floor to management thereby closing the execution gap. Execution of Manufacturing System delivers information that enables the optimization of production activities from order launch to finished goods. Using current and accurate data, Execution of Manufacturing System guides, initiates, responds to, and reports on plant activities as they occur. The Execution of Manufacturing System is made to feed all the other enterprise systems. The contribution to supply chain inventory accuracy and reduction is seen through the Execution of Manufacturing System management of work orders in the plant [8].

Execution of Manufacturing System presents a standard suite of functions that are generic enough to apply to any type of plant foundation. There are eleven generic functions found in Execution of Manufacturing System suite. These eleven functions are:

- Operations/Detailed Scheduling,

- Resource Allocation \& Status, 
- Dispatching Production Units,

- Document Control,

- Product Tracking \& Genealogy,

- Performance Analysis,

- Labor Management,

- Maintenance Management,

- Process Management,

- Quality Management,

- Data Collection Acquisition.

There are many other specific systems depending on the type of production process that Execution of Manufacturing System may need to exchange information with laboratory information system or an energy management system. However, for an Execution System to function it must integrate with the automated control systems that run the plant floor and the ERP to exchange information with management. With this, real-time data can be implemented to allow Execution of Manufacturing System to report and respond to plant activities as they occur, resulting in rapid response to changing conditions [9].

\section{Modern InTELLigenCe TeChNOLOGIES}

- Intelligence Technologies - derivative of AI

\begin{tabular}{|l|l|}
\hline Old Technologies & New Technologies \\
\hline Frames & Fuzzy logic \\
Scripts & Neural networks \\
Production rules & Genetic algorithms \\
Uncertainty rules & Cost - based reasoning \\
Semantic nets & OOP \\
Expert systems & \\
\hline
\end{tabular}

- Newer technologies - Useful to create more powerful \& sophisticated intelligent manufacturing planning systems

- Intelligent manufacturing - true integration is possible

- Program level - More sophisticated (OOP paradigm) (Intelligent agent paradigm)

- Application of newer intelligent technologies -> Integrated Intelligent manufacturing systems

\section{CONCLuSiON}

The main framework of an Intelligent Manufacturing System is elaborated and the designing is explained with the approach of CIMOSA and basic rules are explained, which gives an exposure towards designing of an Intelligent Manufacturing System. The implementation gives the exposure towards steps of in planting an Intelligent Manufacturing System and also how an Intelligent Manufacturing System can be execute in an industry. According to the conceptual theory, the development of Intelligent Manufacturing System methodology is based on the incorporation of artificial intelligence technologies with exact methods.

The various approaches proposed will open up a possibility to make an Intelligent System of Manufacturing of open structure, combining accessible information systems with its sub-system in manufacturing unit using artificial intelligence technologies in order to develop an incorporated atmosphere for complete solution of decision making problems. Intelligent System of 
Manufacturing is most reliable and future oriented of production system development aiming at further optimization and integration of manufacturing processes.

\section{REFERENCES}

[1] Fernando L.F. Almeida, "Designing and implementation of an intelligent manufacturing system", Journal of Industrial Engineering and Management, 2011 - 4(4), 718-745

[2] Galina Setlak, Sławomir Pieczonka, "Design Concept Of Intelligent Management Systems", International Book Series-Information Science and Computing, 142-149

[3] Farid Meziane, Sunil Vadera, Khiary Kobbacy and Nathan Proudlove, "Intelligent Systems in Manufacturing: Current Developments and Future Prospects", 1-31

[4] Dr. Surender Kumar, "Intelligent Manufacturing Systems", B.I.T. Mesra, Ranchi, 1-20

[5] Tomasz Mączka and Tomasz Żabiński, "Platform for Intelligent Manufacturing Systems with Elements of Knowledge Discovery”, Rzeszów University of Technology, Poland, In tech, May 2012, 183-205

[6] Jorge Gamboa-Revilla and Miguel Ramrez-Cadena, "Intelligent Manufacturing Systems: a methodology for technological migration”, Proceedings of the World Congress on Engineering-2008 Vol. II, WCE 2008, July 2-4, 2008, London, U.K.

[7] Weiming Shen, Qi Hao, Hyun Joong Yoon, Douglas H. Norrie, “Applications of agent-based systems in intelligent manufacturing: An updated review", Advanced Engineering Informatics 20, 2006, 415431

[8] Qinglin Guo and Ming Zhang, "Research on Intelligent Manufacturing System Based on MultiAgent”, ICIRA 2008, Part II, LNAI 5315, Springer-Verlag Berlin Heidelberg, pp. 829-838

[9] R. Ramesh, S. Jyothirmai, K. Lavanya, "Intelligent automation of design and manufacturing in machine tools using an open architecture motion controller", Journal of Manufacturing Systems 32 (2013) 248-259

\section{Authors}

Pawan Sharma has completed his B.Tech in Mechanical Engineering, Pursuing M.Tech in Machine Design from RTU, Kota, Rajasthan, India. He has published 21 research papers in the refereed International journals and conferences. His area of research includes CAD/CAM, FEA/FEM, Composite Materials, CFD and Vibration Analysis.

Dr. Manish Bhargava holds M.Tech. in Manufacturing System Engineering, Ph.D. in Mechanical Engineering from MNIT, Jaipur. He has published more than 27 research papers in the refereed International journals and conferences. He has a teaching and research experience of more than 14 years. Currently, He is working as a Professor \& Principal with Maharishi Arvind International Institute of Technology, Kota, Rajasthan, India. His area of research includes CIMS, CAD/CAM, Reliability \& Maintenance, Manufacturing Systems and Material Science.
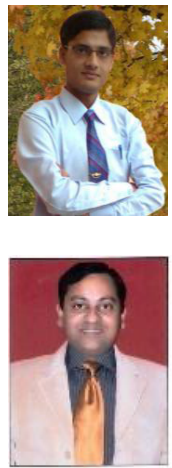